\title{
Rose petal topography mimicked poly(dimethylsiloxane) substrates for enhanced corneal endothelial cell behavior
}

\author{
M. Özgen Öztürk-Öncel ${ }^{\mathrm{a}}$, Fatma Zehra Erkoc-Biradli ${ }^{\mathrm{a}}$, Rufat Rasier ${ }^{\mathrm{b}}$, Merve Marcali $^{\mathrm{c}}$, \\ Caglar Elbuken $^{\mathrm{c}, \mathrm{d}}$, Bora Garipcan ${ }^{\mathrm{a}, ",}$ \\ ${ }^{a}$ Institute of Biomedical Engineering, Boğaziçi University, Istanbul, Turkey \\ ${ }^{\mathrm{b}}$ Department of Ophthalmology, Demiroglu Bilim University, Istanbul, Turkey \\ ${ }^{\mathrm{c}}$ UNAM-National Nanotechnology Research Center, Institute of Materials Science and Nanotechnology, Bilkent University, Ankara, Turkey \\ ${ }^{\mathrm{d}}$ Faculty of Biochemistry and Molecular Medicine, Faculty of Medicine, University of Oulu, 90014 Oulu, Finland
}

\section{A R T I C L E I N F O}

\section{Keywords:}

Corneal endothelium

Biomimetic cell substrate

White rose petal

Polydimethylsiloxane

Collagen IV

Hyaluronic acid.

\begin{abstract}
A B S T R A C T
Low proliferation capacity of corneal endothelial cells (CECs) and worldwide limitations in transplantable donor tissues reveal the critical need of a robust approach for in vitro CEC growth. However, preservation of CECspecific phenotype with increased proliferation has been a great challenge. Here we offer a biomimetic cell substrate design, by optimizing mechanical, topographical and biochemical characteristics of materials with CEC microenvironment. We showed the surprising similarity between topographical features of white rose petals and corneal endothelium due to hexagonal cell shapes and physiologically relevant cell density $\left(\approx 2000\right.$ cells $\left./ \mathrm{mm}^{2}\right)$. Polydimethylsiloxane (PDMS) substrates with replica of white rose petal topography and cornea-friendly Young's modulus (211.85 $\pm 74.9 \mathrm{kPa}$ ) were functionalized with two of the important corneal extracellular matrix (ECM) components, collagen IV (COL 4) and hyaluronic acid (HA). White rose petal patterned and COL 4 modified PDMS with optimized stiffness provided enhanced bovine CEC response with higher density monolayers and increased phenotypic marker expression. This biomimetic approach demonstrates a successful platform to improve in vitro cell substrate properties of PDMS for corneal applications, suggesting an alternative environment for CEC-based therapies, drug toxicity investigations, microfluidics and organ-on-chip applications.
\end{abstract}

\section{Introduction}

Corneal endothelial cells (CECs) are polygonal-shaped cells and they form a monolayer on the posterior surface of the cornea. These cells are specialized for the active pumping of fluids across the cornea to retain its transparency [1]. In young adults, CEC density is $\approx 3000-3500$ cells/ $\mathrm{mm}^{2}$, whereas this number decreases throughout lifetime due to the mitotically inactive nature of CECs [2,3]. Trauma, aging, diseases and intraocular surgical procedures accelerate the decay of CEC density. When cell density drops below a critical level $\left(\approx 500\right.$ cells $/ \mathrm{mm}^{2}$ ), endothelial dysfunction occurs, causing the cornea to lose its optical clarity which leads to impaired vision and subsequent blindness [4,5]. Currently, corneal transplantation or corneal grafts, including fullthickness and selective endothelial keratoplasty are only treatments for restoring corneal endothelium function [6]. Although these methods are successful, immune reaction and rejection of tissues, in addition to worldwide shortage of transplantable donor corneas hinder their wide- use [7]. Thus, there is a high demand for alternative therapies to repair, replace or regenerate corneal endothelium to overcome CEC loss related visual impairment.

Recent studies on cell-based therapy have provided new opportunities to corneal endothelium replacement by using cell transplantation following an in vitro expansion of cells on specific biomaterials $[3,8-10]$. However, functional expansion of CECs is still a challenge, in addition to their limited potential for in vitro proliferation $[11,12]$. Various natural cell substrates were developed for this purpose, including collagen/ hyaluronic acid/ chitosan [13], chitosan/ polycaprolactone [9,14], cross-linked hyaluronan [15], cross-linked collagen/ gelatin/ hyaluronic acid [16] and decellularized cornea layers [17], but poor mechanical properties and high degradation rates lead to the use of synthetic materials $[11,18]$. On the other hand, synthetic materials lack cell binding cites and therefore they require surface modifications, prior to cell culture.

Nature inspires development of smart structures by mimicking

\footnotetext{
* Corresponding author at: Boğaziçi University, Institute of Biomedical Engineering, Kandilli Kampus, Uskudar 34684, Istanbul, Turkey.

E-mail address: bora.garipcan@boun.edu.tr (B. Garipcan).
} 
various creatures, like beehives, spider silk networks, gecko feet, shark skin and lotus leaves $[19,20]$. As natural materials exhibit unique microand nanoscale cues with good biocompatibility, biomimetics have been used as a promising approach in cell substrate design [21-23]. In native environment, CECs are in direct contact with underlying Descemet's membrane, which is mainly composed of Collagen type IV (COL 4) and VIII (COL 8) [24]. As the microenvironment of cells and the interaction in between them regulate cellular behavior, properties of Descemet's membrane and corneal extracellular matrix (ECM) have been considered in designing new biomaterials $[4,25,26]$. Palchesko et al. focused on the chemical and mechanical properties of corneal ECM and prepared polydimethylsiloxane (PDMS) substrates with Descemet's membrane-like mechanical properties. After coating with several ECM proteins, they reported that $50 \mathrm{kPa}$ PDMS with COL 4 coating resulted a significant increase in CEC proliferation, in addition to improved expression of phenotypic markers [4]. Teo et al. developed various micro- and nanoscale geometrical surface patterns (pillars and wells) on PDMS substrates inspired by topographical features of Descemet's membrane. Among them, the nanopillar surface topography was found to be the most suitable pattern to obtain CEC culture with typical cell shape and better functionality [27]. In a similar study, patterned tissue culture polystyrene (TCPS) was confirmed to significantly improve CEC expansion and CEC-related protein expression [12]. A more recent work described the effect of PDMS with Descemet-like surface topography on the differentiation of mesenchymal stem cells (MSC) into corneal endothelial-like cells [28]. Although these studies are inspired by the microenvironment of corneal endothelium, they focused only on one or two important parameters of ECM characteristics. However, combined effects of mechanical, topographical and biochemical properties of cell microenvironment regulate cell behavior in vivo and thus a holistic approach is required when designing cell substrates to obtain desired in vitro cell response [29].

PDMS is a synthetic, non-toxic and optically transparent polymer with adjustable stiffness, surface chemistry and excellent properties for structure replication [30,31]. Here, we developed PDMS cell substrates within the bulk modulus range of cornea [32] and adjusted surface topographical and biochemical properties according to the CEC microenvironment. Young's modulus of 30:1 PDMS base to curing agent ratio was found to be a cornea-friendly stiffness with $211.85 \pm 74.9 \mathrm{kPa}$. Additionally, we took the advantage of naturally occurring patterns rose petals (negative reliefs), to control cell substrate topographies. In the literature, red rose petal mimetic/inspired polymer films have been investigated for their superhydrophobic and highly adhesive surface properties [33-35]. The microstructure of rose petals exhibited compactly arranged micropapillae with nanoscaled folds on each micropapillae [36], which may provide a suitable environment for CEC culture. Thus, we examined both red and white rose petal-mimetic PDMS surfaces and it is to our surprise that the structure of white rose petals is very similar to the natural CEC microenvironment topographical features. Inverse reliefs (negative replicate) of white rose petal topographies were used in the PDMS substrate surface design to support cell culture. Furthermore, substrate surfaces were chemically modified with corneal ECM components, whereas in many CEC studies with PDMS, simple techniques (like plasma oxygenation or physical adsorption) were used to make substrates suitable for cell culture. Since these techniques are stable for a very short while, we used stable chemical linkages to modify PDMS with either Collagen IV (COL 4) - a predominant collagen in Descemet's membrane [24], or Hyaluronic acid (HA) an important ECM component of cornea [37]. The combination of these mechanical, topographical and chemical improvements of PDMS substrates enhanced in vitro CEC expansion and functional marker expression. This extensive approach can be easily adapted to cornea-on-a-chip applications for drug design or used as a successful cell substrate alternative in corneal cell therapy to decrease the need of donor corneas.

\section{Material and methods}

\subsection{Investigation of cornea-friendly PDMS stiffness}

PDMS substrates with various base and curing agent concentrations (10:1, 15:1, 20:1 and 30:1) were prepared [38] and cured at $70^{\circ} \mathrm{C}$ for 4 h. Young's modulus measurements of PDMS substrates were performed using a nanoindenter (CellHesion ${ }^{\circledR 200}$, JPK) in hydrated conditions with a CONT cantilever $(0.2 \mathrm{~N} / \mathrm{m}$ force constant and $13 \mathrm{kHz}$ resonance frequency, Nanoworld) in contact mode and 7 samples were analyzed for each group. Young's moduli of different PDMS substrates were calculated according to the Hertz model.

\subsection{Preparation of rose topography mimicked PDMS}

White (Rosa Pascali) and red roses (Rosa Damascena) were purchased from a local flower shop. In this study, soft lithography was used to produce rose petal relief negative pattern on PDMS cell substrates. To use the same pattern in cell substrates, the rose petal relief negative replicate was copied for several times by using the first positive replicate (gold coated) as a mold. Briefly, rose petal topography mimicked negative (-) replica was prepared by mixing 10:1 ratio of PDMS base and curing agent (PDMS, Sylgard 184; Dow). Rigorously stirred mixture was degassed completely and poured onto rose petals. Red and white rose petals were used both in fresh and dried (petals were fixed onto a cork board and allowed to dry under room conditions) form. After $4 \mathrm{~h}$ of curing at $70^{\circ} \mathrm{C}$, replicas were cleaned by sonicating in DI water, absolute ethanol and DI water, respectively. Both negative and positive replicas were sputter coated with a thin layer of gold (Quorum SC7640 high resolution sputter coater, $1.5 \mathrm{kV}, 10 \mathrm{~mA}$ ), before using as a mold. 15:1 PDMS base to curing agent ratio was used for the positive $(+)$ replica, as it would be easier to peel off while using PDMS with different base to curing agent ratios. Finally, (white) rose petal topography mimicked cell substrates were prepared with 30:1 PDMS (Section 3.2). This procedure is schematically given in Fig. 1. Positive molds supported at least 10 replications (Supplementary Information, SI, Fig. S1). Mimicked substrates were characterized by a Scanning Electron Microscope (SEM, XL30, Philips) and an optical profilometer (Zygo, CT) for determining morphology and pattern dimensions, respectively.

\subsection{Surface functionalization of PDMS substrates with $C O L 4$ and $H A$}

PDMS substrate surfaces were modified with COL 4 and HA using EDC/NHS coupling chemistry. First, surfaces were activated via oxygen plasma for $60 \mathrm{~s}(50 \mathrm{sccm} \mathrm{O}$ flow at 200 mTorr pressure, March Plasma Systems) [39] and then they were immersed into 10\% (3-aminopropyl) triethoxysilane (APTES) in absolute ethanol to form amine groups (PDMS-NH ${ }_{2}$ ) [39,40]. $1 \mathrm{mg} / \mathrm{mL} \mathrm{HA} \mathrm{(Acros,} \mathrm{251770010)} \mathrm{and} 0.5 \mathrm{mg} / \mathrm{mL}$ COL 4 (Sigma C5533) solutions were prepared in 1:1 EDC and NHS containing MES buffer (50 mM, pH 5.0) and stirred for $30 \mathrm{~min}$ [41,42]. Finally, PDMS- $\mathrm{NH}_{2}$ substrates were incubated in these solutions at room temperature (RT) overnight with subsequent rinsing in the following day with MES buffer and DI water (Fig. 2).

\subsection{Characterization of functionalized PDMS substrates}

Surface modification of PDMS substrates with COL 4 and HA was confirmed by using water contact angle (WCA) measurements (CAM $100, \mathrm{KSV}$ ) with a fixed amount of DI water at RT. In each experimental group, 5 samples were analyzed for their wettability properties.

Changes in surface chemistry after modification were monitored using an X-ray photoelectron spectrophotometer (XPS) with aluminum $\mathrm{K}-\alpha$ radiation (Thermo Scientific). $150 \mathrm{eV}$ pass energy was used for the investigation of survey spectra, whereas $50 \mathrm{eV}$ was used for high resolution.

COL 4 and HA functionalization of PDMS substrates were visualized 


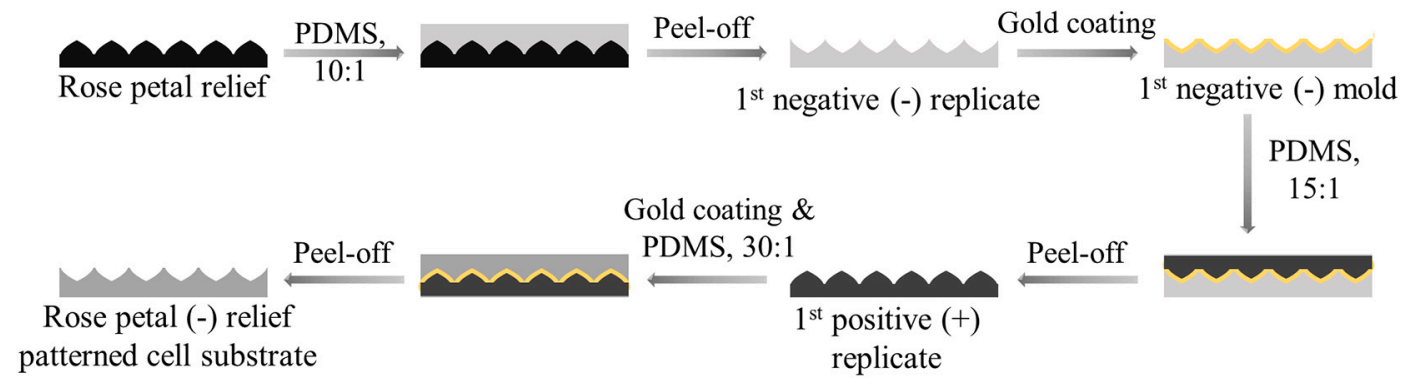

Fig. 1. Schematic procedure of rose petal topography mimicked PDMS substrate preparation.

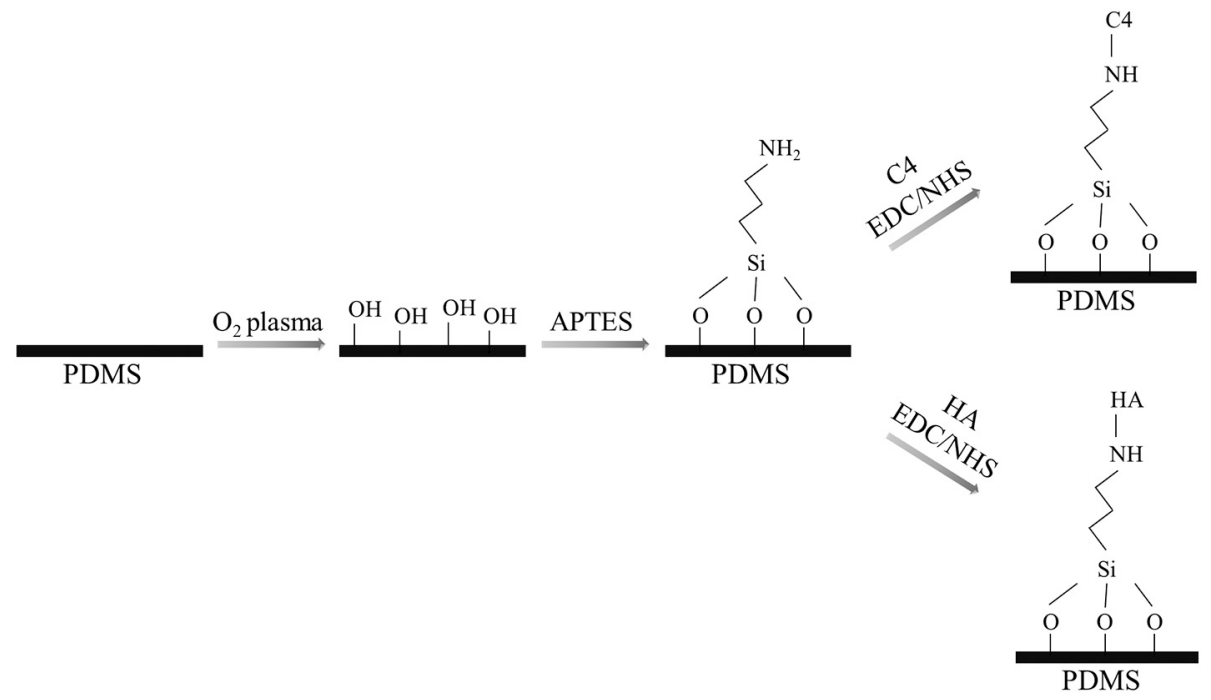

Fig. 2. Functionalization of PDMS substrates with COL 4 and HA.

by using immunofluorescent staining. Initially, blocking was performed to eliminate unspecific binding via $22.52 \mathrm{mg} / \mathrm{mL}$ glycine containing $1 \%$ BSA in PBST (0.1\% Tween-20 in PBS) for an hour. Then, substrates were incubated with primary antibodies of anti-collagen IV (ab6586, 1:100) and anti-hyaluronic acid (ab53842, 1:100) in 1\% BSA containing PBST overnight at $4{ }^{\circ} \mathrm{C}$. After rigorous rinsing of substrates with PBS, secondary antibodies of anti-rabbit IgG H\&L (ab150062, Alexa Fluor ${ }^{\circledR 555}$, 1:200) and anti-sheep IgG H\&L (ab150177, Alexa Fluor ${ }^{\circledR} 488,1: 200$ ) were added to each sample and incubated at RT for an hour. Finally, immunofluorescent signals were visualized using appropriate excitation filters of a fluorescence microscope (DM IL, Leica).

\subsection{Corneal endothelial cell culture}

Bovine CECs (BCE C/D-1b, ATCC ${ }^{\circledR}$ CRL-2048 ${ }^{\mathrm{TM}}$ ) were cultured on PDMS substrates in 24 well tissue culture plates (TCP) with a density of $1 \times 10^{5}$ cells/well, using 10\% Fetal Bovine Serum (FBS, Merck) supplemented DMEM High glucose with L-Glutamine and Sodium Pyruvate (Biosera). Cells were incubated at $37{ }^{\circ} \mathrm{C}$ with $5 \% \mathrm{CO}_{2}$ in a humidified environment. PDMS substrates were sterilized before cell culture with 70\% ethanol, sterile DI water and UV exposure. CEC cell behavior was investigated on both flat native PDMS (PDMS), COL 4 functionalized PDMS (PDMS-C4), HA functionalized PDMS (PDMS-HA) and white rose petal negative relief topography mimicked versions of these substrates (PDMS-R, PDMS-C4-R and PDMS-HA-R, respectively) with a control group of TCP.

\subsection{Cell proliferation assay}

Alamar blue assay (AlamarBlue ${ }^{\mathrm{TM}}$, Bio-Rad) was used to investigate
CEC proliferation on various PDMS substrates on days 1, 3 and 7. Briefly, cell culture media was removed and $10 \%$ alamar blue containing fresh media was added to cells on these specific days. Cells were incubated for $4 \mathrm{~h}$ and optical absorbance of each experimental group was recorded on a micro plate reader spectrophotometer (Bio-Rad, iMark) at 570 and $595 \mathrm{~nm}$ [31].

\subsection{Morphological staining}

Cellular morphology on functionalized and white rose petal patterned PDMS substrates was investigated via actin cytoskeleton staining (Alexa Fluor 488 Phalloidin, Thermo Fisher) on the $7^{\text {th }}$ day of CEC culture. Cells were fixed in $4 \%$ formaldehyde and permeabilized by immersing into $0.1 \%$ Triton X-100 containing PBS. After blocking was completed in 1\% BSA for $20 \mathrm{~min}$, actin cytoskeleton staining solution (in $1 \%$ BSA) was applied. DAPI counterstaining (Thermo Fisher) was used to visualize cell nuclei. Images were recorded with appropriate filters of a fluorescence microscope (DM IL, Leica) [31].

\subsection{Immunocytochemistry}

On the 7th day of CEC culture on substrates, cells were fixed and permeabilized as instructed in Section 2.7. Blocking and immunocytochemical staining were performed using the same procedure as in Section 2.4. Anti-sodium potassium ATPase primary antibody (ab76020, EP1845Y, 1:100) and anti-rabbit IgG H\&L secondary antibody (ab150062, Alexa Fluor ${ }^{\circledR 555, ~ 1: 200) ~ w e r e ~ u s e d ~ t o ~ l a b e l ~} \mathrm{Na}^{+} / \mathrm{K}^{+}$ ATPase, and DAPI was used to visualize cell nuclei. 


\subsection{Western blot analysis}

Western blot analyses were performed on the 7th day of CEC culture and expressions of CEC-relative markers $\mathrm{Na}^{+} / \mathrm{K}^{+}$ATPase, collagen type IV, N-cadherin and zonula occludens-1 (ZO-1) were investigated on PDMS substrates. Briefly, total proteins were extracted and lysed in $2 \times$ Laemmli buffer and equalized amounts of proteins were loaded into 4-10\% polyacrylamide gels (Sigma-Aldrich). Then, they were resolved under $130 \mathrm{~V}$ (Mini protean, Bio-Rad) and transferred to PVDF membranes (Transblot Turbo, Bio-Rad). After blocking was completed using $5 \%$ non-fat milk containing PBST, membranes were incubated with antisodium potassium ATPase (ab76020, EP1845Y), anti-collagen IV (ab6586), anti-N-cadherin (ab18203) primary antibodies overnight at 4 ${ }^{\circ} \mathrm{C}$. Anti- $\beta$-actin (ab8226) was chosen to be the loading control. On the following day, membranes were rinsed extensively with PBST and incubated with corresponding horseradish peroxidase (HRP)-labeled secondary antibodies (ab6721, and ab6789) for 1 h. 3,3',5,5'-tetramethylbenzidine chromogenic substrate (Thermo Fisher) was used for the visualization of bands on the membranes and their intensities were calculated using ImageJ.

\subsection{Statistical analysis}

Graphpad (Prism) software was used to conduct all statistical analyses with one-way analysis of variance (ANOVA) and Tukey multiple comparison test. $p$ values lower than 0.05 were regarded as statistically significant. Data were given as mean \pm standard deviation (SD).

\section{Results}

\subsection{Topographical features of rose petal mimicked PDMS}

Soft lithography was used to transfer rose petal's positive and negative reliefs topographical cues on PDMS substrates. Fig. 3A summarizes SEM images of (i) fresh red, (ii) dry red, (iii) fresh white and (iv) dry white rose petal patterned features on 15:1 PDMS surfaces (positive replicas). Herein, both micro- and nano-sized cues were successfully replicated. Due to the shrinkage of cells in dry petals, cell shapes were disrupted leading to reduced cell number and increased cell-to-cell distances. Therefore, they were not preferred as cell substrates for CECs. In both fresh rose petals patterned ones; cell number is in the range of physiologically relevant CEC density $\left(\approx 2000\right.$ cells $\left./ \mathrm{mm}^{2}\right)$.
A.
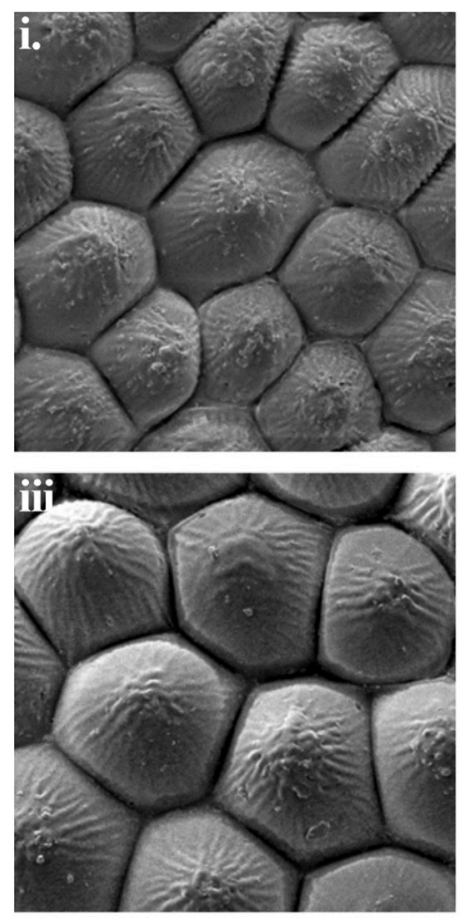
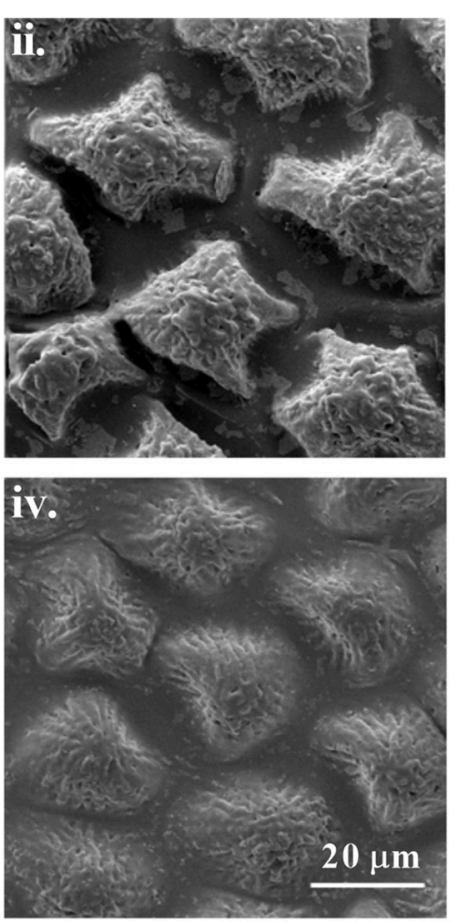

C.

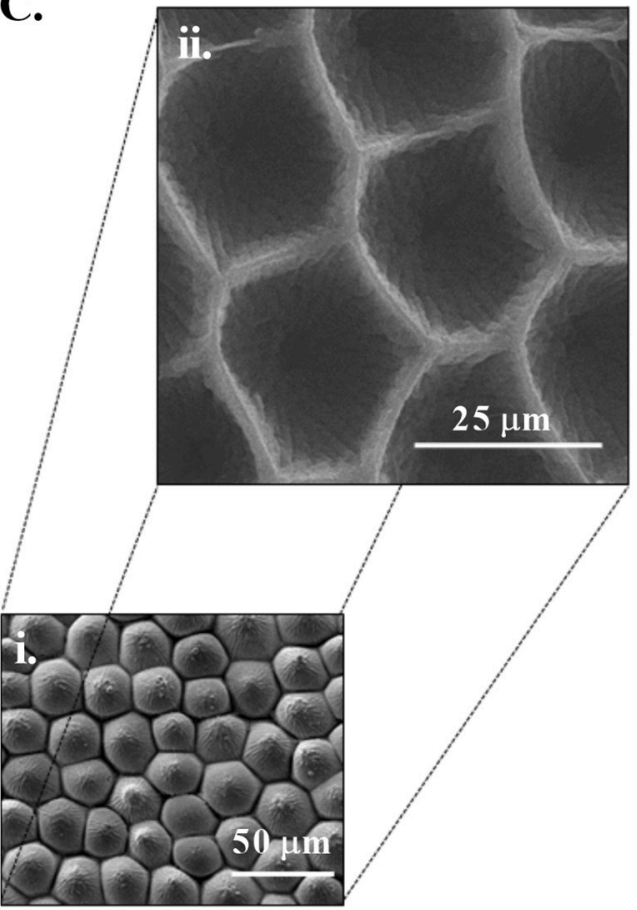

B.
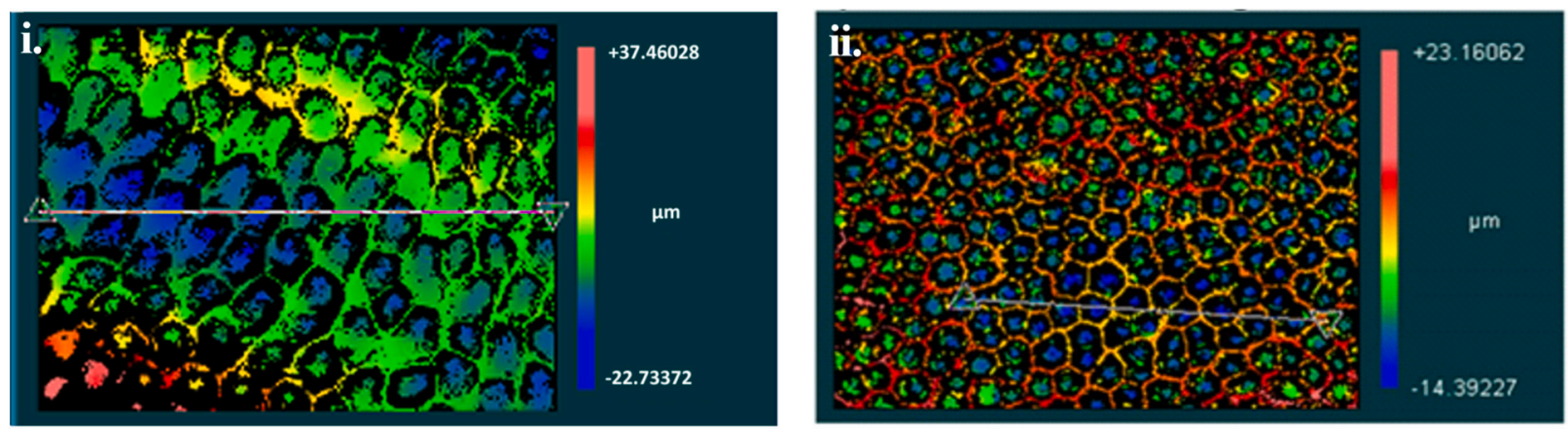

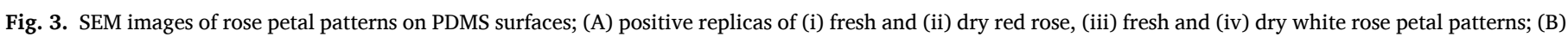

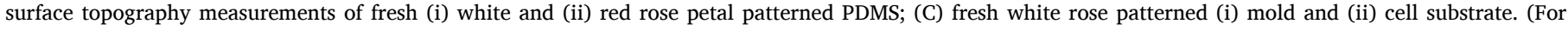
interpretation of the references to colour in this figure legend, the reader is referred to the web version of this article.) 
Microgroove mean depths ( $N=30$ measurements using optical profilometer over 3 PDMS replicas) of the patterned PDMS were calculated to be $12.9 \mu \mathrm{m}$ and $6.6 \mu \mathrm{m}$ for red and white rose, respectively (Fig. 3B). Among them, white rose patterned one ensured CEC-like depth [43]. Furthermore, fresh white rose petal provided better CEC shape-imitative hexagonal cells than red ones. Thus, we used white rose petals (Rosa Pascali) for the fabrication of patterned cell substrates in the study. In Fig. 3C, SEM images of (i) white rose petal replicating mold and (ii) white rose petal topography mimicked PDMS cell surfaces were given. Highly ordered hexagonal shapes and nano-scale cues in Fig. 3C(ii) proved both successful replication and CEC shape-imitative cell substrate production.

Replicating capacity of PDMS molds were tested by using a marked PDMS mold for 10 replications. SEM images of fabricated substrates confirmed that a rose petal patterned PDMS mold could be used at least 10 times without causing any disruptions (Fig. S1).

\subsection{Mechanical properties of PDMS substrates}

PDMS substrates were prepared in decreasing curing agent concentrations $(10: 1,15: 1,20: 1$ and 30:1) to obtain substrates with a wide stiffness range. Nanoindentation was used for the characterization of these various PDMS substrates and Young's modulus values were given in Fig. $4 \mathrm{~A}$ as $2105.3 \pm 155.6,1387.57 \pm 152.9,683.43 \pm 188.7$ and $211.85 \pm 74.9 \mathrm{kPa}$ for 10:1, 15:1, 20:1 and 30:1 PDMS base and curing agent ratios, respectively. All these formulations provided successful pattern replications, whereas lower amounts of PDMS curing agent than 30:1 resulted sticky substrates. Among 10:1-30:1 PDMS substrates, the Young's modulus of 30:1 PDMS (211.85 $\pm 74.9 \mathrm{kPa})$ was found in the cornea-friendly range, which is between 200 and $290 \mathrm{kPa}$ [32,44-46] and PDMS with 30:1 base to curing agent ratio was used for the fabrication of all cell substrates. Since oxygen plasma was used to activate PDMS surfaces, prior to modification, the effect of this technique on substrate stiffness was also investigated by using nanoindentation (Fig. S3).

\subsection{Characterization of PDMS surface functionality}

COL 4 and HA functionalization of PDMS substrates were confirmed via WCA measurements for the alteration in surface hydrophobicity, XPS analysis and immunofluorescent staining for surface chemical and biochemical investigation.

Wettability properties of various PDMS substrates were investigated to show the effect of surface functionalization and results are given in Fig. 4B. Untreated PDMS surfaces displayed a hydrophobic nature with a water contact angle of $104.6^{\circ} \pm 4.3^{\circ}$, which was strongly reduced after
A.

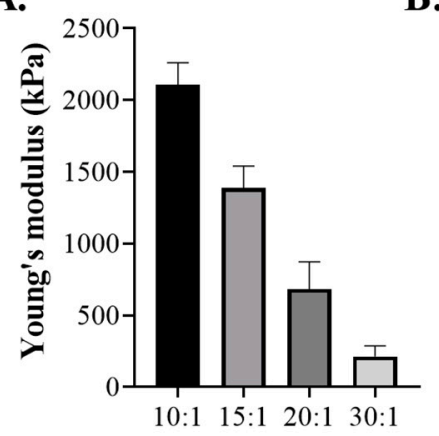

Base to curing agent ratios

B.

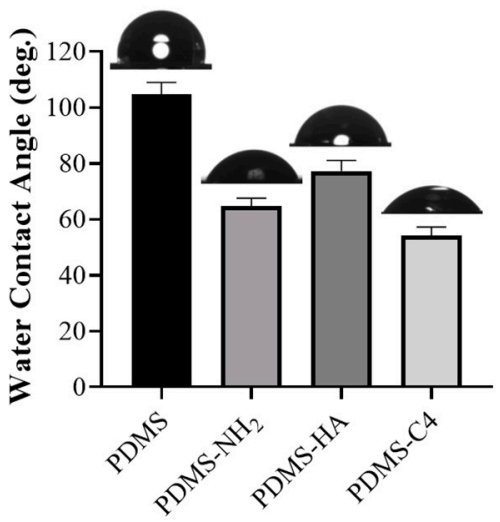

C.

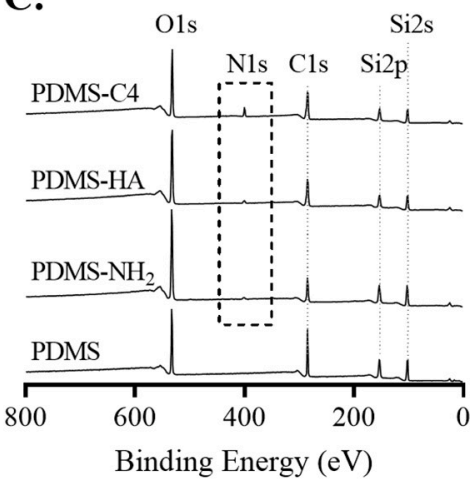

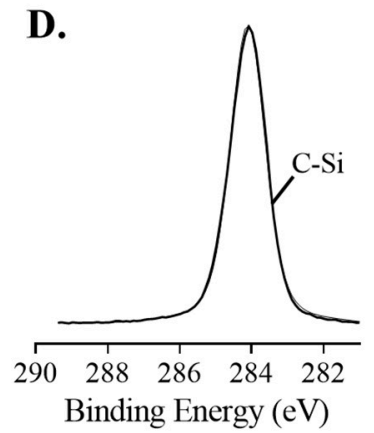

E.

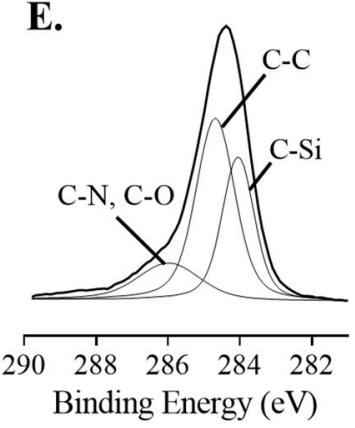

F.

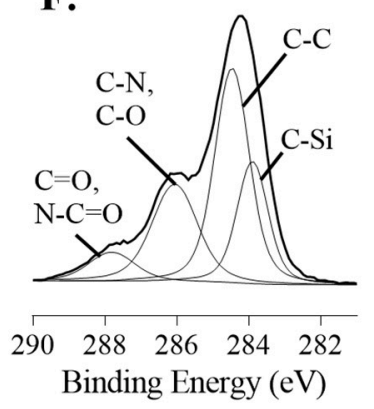

G.

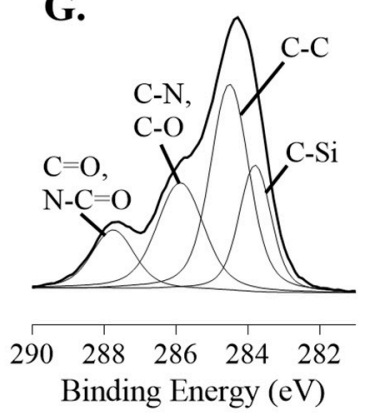

H.

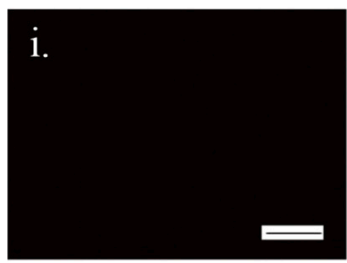

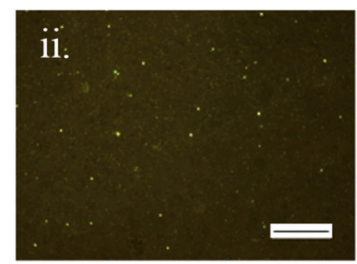
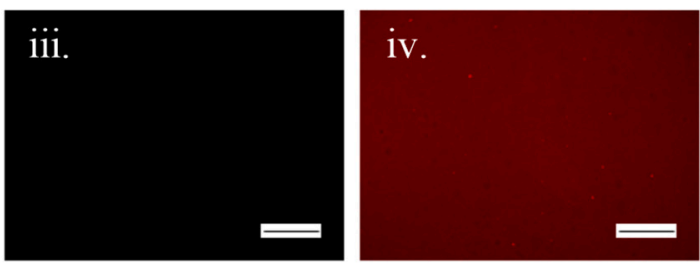

Fig. 4. Characterization of PDMS substrates. (A) Nanoindentation measurements of varying PDMS base and curing agent formulations $(n=7$, $* * * * p<0.0001)$; (B) WCA analysis $(n=5)$ and (C) XPS survey spectra of native PDMS and APTES, HA and COL 4 functionalized PDMS. (D) High resolution C1s spectra of native PDMS, (E) PDMS-NH ${ }_{2}$, (F) PDMS-HA and (G) PDMS-C4. (H) Immunofluorescent staining against anti-hyaluronic acid on (i) PDMS and (ii) PDMS-HA; against anti-collagen IV on (iii) PDMS and (iv) PDMS-C4. $\mathrm{n}=5$, scale bar $=200 \mu \mathrm{m}$. 
oxygen plasma treatment and APTES modification $\left(64.7^{\circ} \pm 2.8^{\circ}\right)$ due to the formation of hydrophilic amine groups. After HA functionalization, PDMS surfaces became more hydrophobic than PDMS- $\mathrm{NH}_{2}$ with a WCA of $77.2^{\circ} \pm 3.8^{\circ}$, whereas PDMS-C4 showed the lowest contact angle of $54.1^{\circ} \pm 3.1^{\circ}$.

XPS survey (Fig. 4C) and high-resolution spectra were shown (Fig. 4D-G) for PDMS, PDMS-NH 2 , PDMS-HA and PDMS-C4. In survey spectra, all PDMS related peaks of Si2s, Si2p, C1s and O1s were detected [31]. After modification with APTES, N1s peak was shown at $400.4 \mathrm{eV}$ to confirm the incorporation of $-\mathrm{NH}_{2}$ functional group. When HA or COL 4 were immobilized on PDMS surfaces, there were significant rises in C1s and N1s. This is a clear indication of introducing biomolecules to PDMS surfaces featuring various carbon-nitrogen functionalities. Further investigation was supplied by the high-resolution C1s core-level spectra. Four different $\mathrm{C}$ species were specified based on their binding energies, $\mathrm{C}-\mathrm{Si}$ at $\approx 283.7 \mathrm{eV}, \mathrm{C}-\mathrm{H}, \mathrm{C}-\mathrm{C}$ at $\approx 284.5 \mathrm{eV}, \mathrm{C}-\mathrm{N}, \mathrm{C}-\mathrm{O}$ at $\approx 285.8$ $\mathrm{eV}$ and $\mathrm{N}-\mathrm{C}=\mathrm{O}, \mathrm{C}=\mathrm{O}$ at $\approx 287.8 \mathrm{eV}[41,47,48]$. The appearance of $\mathrm{C}-\mathrm{C}$, $\mathrm{C}-\mathrm{O}$, and $\mathrm{C}-\mathrm{N}$ was attributed to the successful chemical modification with APTES, HA and COL 4. Furthermore, the presence of surface amidetype functionalities $(\mathrm{N}-\mathrm{C}=\mathrm{O})$ confirms the conjugation of $\mathrm{PDMS}-\mathrm{NH}_{2}$ with HA or COL 4. In order to confirm XPS data, further surface chemical composition analyses were done by using fourier transform infrared spectroscopy (FTIR). Distinctive peaks at $1650,1680 \mathrm{~cm}^{-1}$ for PDMS-HA [41] and at $1657 \mathrm{~cm}^{-1}$ for PDMS-C4 [49,50] were recorded to show successful surface functionalization, in addition to broad peaks around $\approx 3400 \mathrm{~cm}^{-1}$ in both modified groups, associated with $\mathrm{N}-\mathrm{H}$ and $-\mathrm{OH}$ stretching [41,42] (Fig. S4).

Immunofluorescent staining was further used to show the uniformity of HA or COL 4 functionalization on PDMS- $\mathrm{NH}_{2}$ (Fig. $4 \mathrm{H}$ and Fig. S5). No fluorescent signals were observed in native PDMS for both antihyaluronic acid and anti-collagen IV staining [Fig. 4H(i) and (iii)], whereas uniform staining of HA (in green) and COL 4 (in red) were visualized, attributable to the HA or C4 functionalization [Fig. 4H(ii) and (iv)], [41,50].

\subsection{In vitro growth and morphology of CECs}

CEC proliferation and actin cytoskeleton were evaluated on flat and white rose negative relief patterned native, HA functionalized and COL 4 functionalized PDMS surfaces over 7 days. The metabolic activity of CECs on various PDMS substrates was determined via Alamar blue assay on days 1, 3 and 7. The effect of only surface chemical modification on CEC proliferation was given in Fig. 5A, relative to reduced alamar blue percentages. According to the figure, CECs on all substrates were in a tendency of increasing in number with time and remained viable for 7 days. This is a certain indication of non-toxic effect of both native and modified PDMS. Among all PDMS substrates, PDMS-C4 clearly enhanced CEC proliferation significantly $(p<0.0001)$ for the whole cell culture period. White rose negative relief patterning of PDMS increased the cell number on all PDMS surfaces (Fig. 5B) and with PDMS-C4-R, a TCP-like proliferative environment was achieved for CECs on days 3 and 7. HA functionalization of PDMS did not show any improvements on CEC proliferation relative to native PDMS. Thus, white rose patterningrelated cell proliferation was investigated on native and COL 4 modified PDMS (Fig. 5C). This effect was clearly visible on day 7 with a statistically increased cell metabolic activity on patterned versions of each group $(p<0.0001)$. In addition to promotive effect of white rose mimicked patterning, COL 4 functionalization resulted an improved CEC
A.

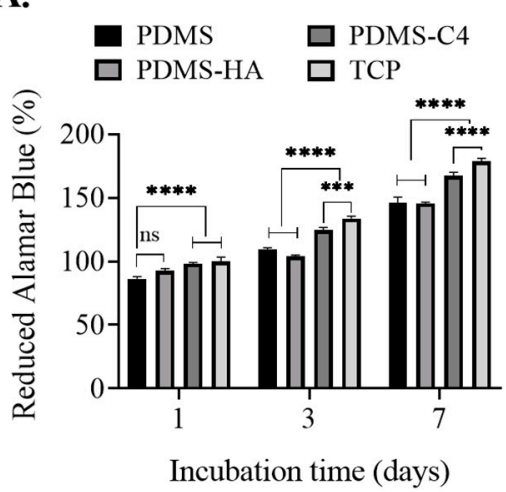

B.

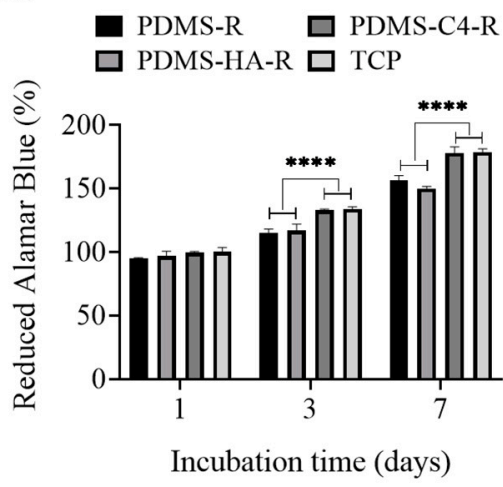

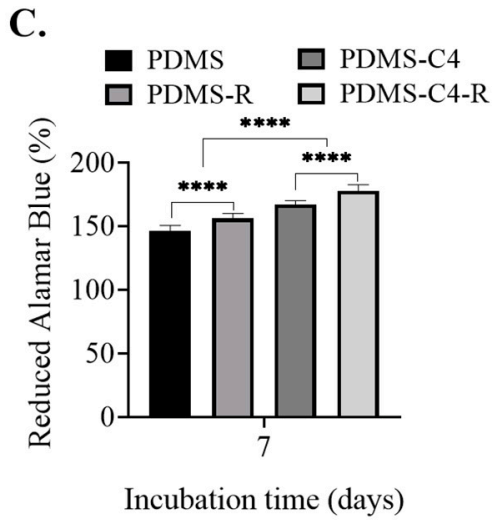

C.

Incubation time (days)

D.
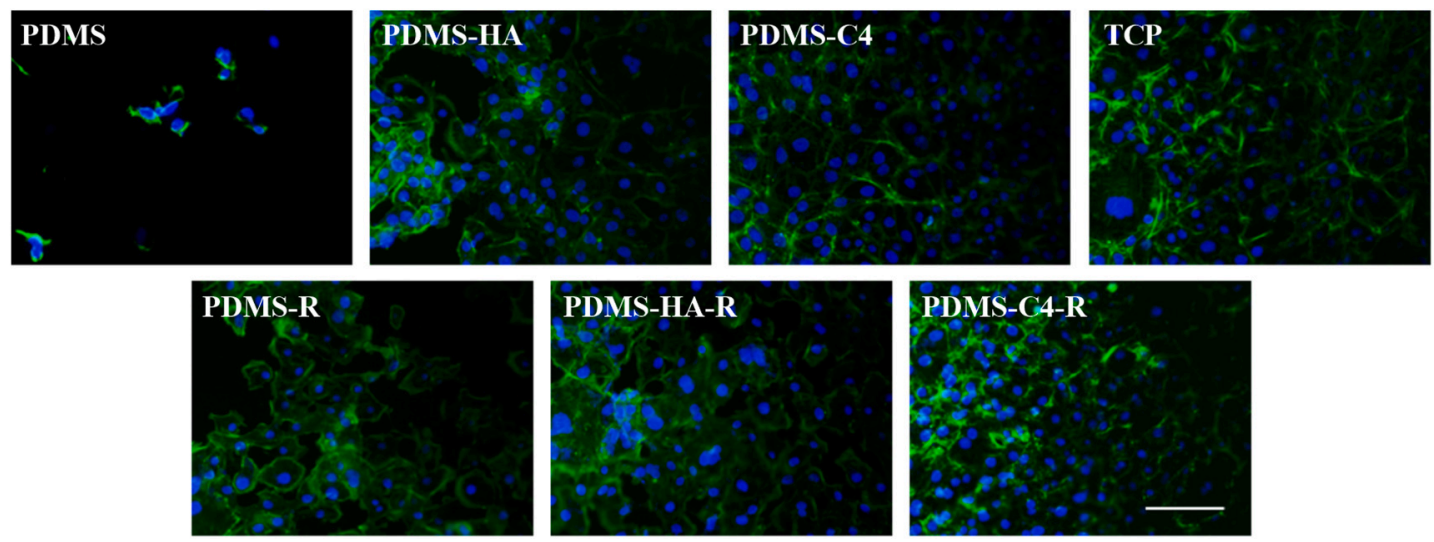

Fig. 5. CEC proliferation and morphology on PDMS substrates. Reduced alamar blue (\%) with relative CEC proliferation on (A) flat and (B) white rose patterned native PDMS, PDMS-HA, PDMS-C4 and TCP over 7 days and (C) CEC proliferation on flat and white rose patterned PDMS and COL 4 on day 7 ( $n=5$, *** $p<0.001$ and ${ }^{* * *} p<0.0001$ ). (D) Actin cytoskeleton (green) and nuclei (blue) staining of CECs on PDMS substrates (Scale bar $=100 \mu \mathrm{m}$ ). (For interpretation of the references to colour in this figure legend, the reader is referred to the web version of this article.) 
bioactivity $(p<0.0001)$.

Cellular morphology on PDMS substrates were investigated on day 7 via actin cytoskeleton staining and fluorescence images of CECs on various surfaces were given in Fig. 5D. Separate images were also given in SI (Fig. S8). Very few attached cells were found on flat native PDMS, supporting the proliferation analysis. Both patterning and surface chemical modification increased the number of attached cells on PDMS surfaces. Furthermore, patterned PDMS-C4 provided the most densely CECs population with well-defined actin fibers organization.

\subsection{Investigation of CEC phenotype}

Expression of CEC-relative marker $\mathrm{Na}^{+} / \mathrm{K}^{+}$ATPase was investigated (Fig. 6) to verify the CEC phenotype via immunofluorescent staining. Separate images were also given in SI (Fig. S9). All experimental groups gave positive signals with varying dispersion. In flat native and HA functionalized PDMS, $\mathrm{Na}^{+} / \mathrm{K}^{+}$ATPase signals were not intense, whereas PDMS-C4 provided the highest $\mathrm{Na}^{+} / \mathrm{K}^{+}$ATPase activity, including the positive control group-TCP. White rose patterning resulted in an increase in stained areas for all groups. Mean fluorescence intensities of $\mathrm{Na}^{+} / \mathrm{K}^{+}$ATPase staining in Fig. 6 were calculated relative to control group, TCP by using ImageJ software and given in SI (Fig. S10). Among all plain and patterned substrates, uniform distribution and the highest staining intensity were achieved on PDMS-C4-R with densely populated CECs.

Further investigation of CEC phenotype specific markers was conducted with the cell substrates that showed enhanced cell responses in $\mathrm{Na}^{+} / \mathrm{K}^{+}$ATPase immunostaining: PDMS-C4, PDMS-C4-R and TCP. Western blot analysis on Fig. 7 demonstrated that depositions of CECrelated functional proteins, $\mathrm{Na}^{+} / \mathrm{K}^{+}$ATPase, N-Cadherin and Collagen IV were detected in cells on all these substrates with relatively highest expressions on PDMS-C4-R. Confirming immunostaining results, $\mathrm{Na}^{+} /$ $\mathrm{K}^{+}$ATPase expression of cells was significantly higher on patterned PDMS-C4, than flat one ( $\left.{ }^{*} p<0.05\right)$, similar to another CEC-specific marker, N-Cadherin. Although PDMS-C4-R group showed the highest expression, the difference between PDMS-C4-R and TCP was not significant for both $\mathrm{Na}^{+} / \mathrm{K}^{+}$ATPase and N-Cadherin (Fig. 7A-B). However, deposition of Collagen IV was significantly up-regulated on patterned PDMS-C4 than its flat version $(* * p<0.01)$ and TCP $(* p<0.05)$. Collagen IV is one the most important ECM components for the maintenance of healthy CEC hexagonal morphology. Increased expression of Collagen IV, in addition to $\mathrm{Na}^{+} / \mathrm{K}^{+}$ATPase and $\mathrm{N}$-Cadherin implied that white rose negative relief patterned PDMS substrates enhanced CECspecific functions, in vitro.

\section{Discussion}

In this study, we developed biomimetic PDMS cell substrates having a cornea-friendly stiffness, white rose petal negative relief patterned surface topography and corneal ECM-like surface biochemistry. A successful cell substrate should support in vitro cell adhesion, proliferation and cell type specific functions, mimicking the in vivo cell environment. Therefore, there is growing interest on preparation of natural cell microenvironment-like substrates having well-regulated mechanical, physical and biochemical properties. Here, we focused on CECs, as they are one of the cell types, which cannot regenerate in vivo and the decrease in cell number would eventually cause certain diseases and vision loss $[1,11]$. Keratoplasty has been the main treatment of such corneal endothelial diseases, however due to the limited availability of donor tissues, new approaches are required [51]. The major challenge in the development of alternative methods is the expansion of functional CECs in vitro. Production of successful cell substrates for functional CECs proliferation in vitro would not only enable treatment opportunities to more patients using lower number of donor corneas but also would provide an alternative environment to drug design or cell therapy applications. To address this need, we have developed a cell substrate for in vitro CEC culture (PDMS-C4-R) with optimized surface properties.

Micro- to nano-scale topographical features on materials are sensed by cells and modulate their behavior [52,53]. Various cell types, like fibroblasts [54], osteoblasts [55] or MSCs [56], have been investigated to show the effect of substrate surface topography on cell response. Similarly, in corneal regeneration and reconstruction, numerous studies demonstrated the influence of micro- and nanoscale geometrical cues on cell adhesion, maturation, proliferation, morphology or differentiation [57]. Simple pattern cues (grooves, wells, pillars, pits, etc.) have been fabricated for corneal epithelial cells [58], corneal keratinocytes [59], corneal keratocytes [60], corneal stromal cells [61] or CECs [62]. However high precision design considerations on natural microenvironment architecture are required to produce substrate surfaces with enhanced biomimetic topography. In their native microenvironment, CECs are in direct contact with the nanotopography of underlying Descemet's membrane [63]. Inspired by these isotropic cues, micro- and nanoscale pillars and wells were formed on various substrates, like PDMS or TCP, and these patterned substrates provided enhanced CEC proliferation and functional marker expression [12,27,62]. Instead of producing geometrical structures on cell substrates, we took the advantage of naturally occurring nano- and micropatterns with healthy corneal endothelium-like topography: rose petals. Red and white (both in dry and fresh form) rose petal topographies were investigated with SEM after PDMS replication (Fig. 3A). Fresh white rose petal mimicked surfaces showed healthy CEC shape-like hexagonal patterns [Fig. 3C(i)]
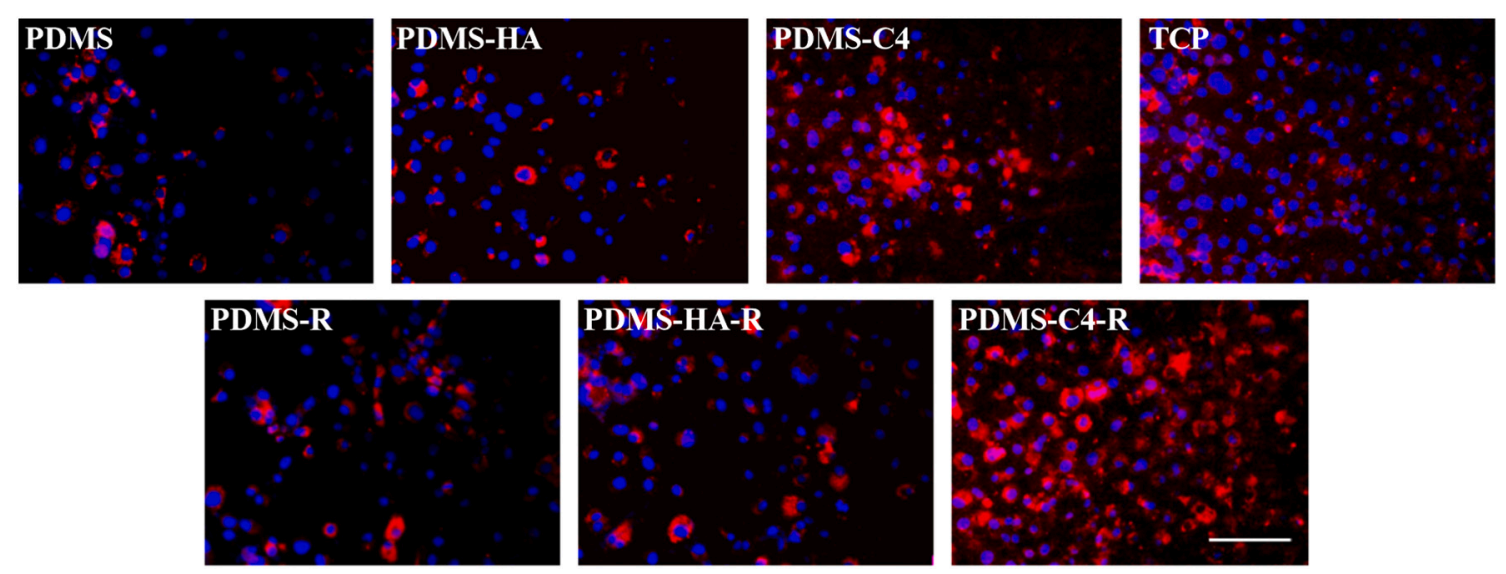

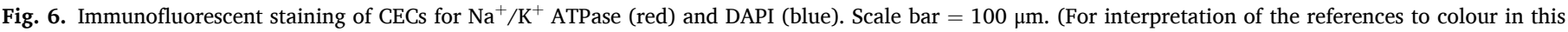
figure legend, the reader is referred to the web version of this article.) 
A
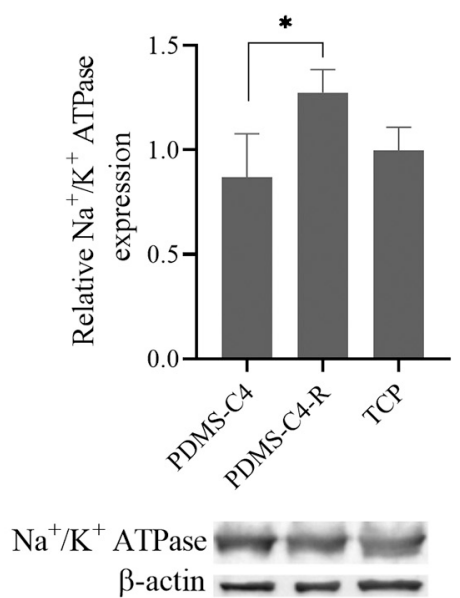

B
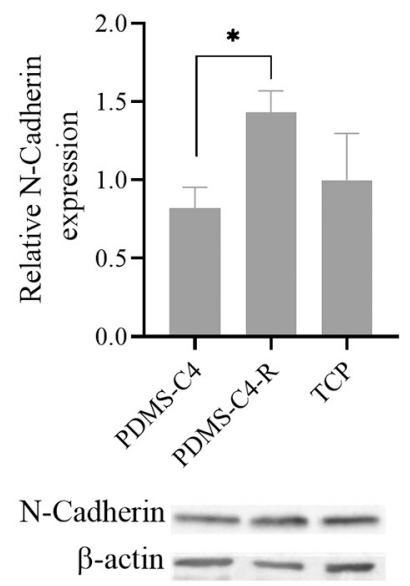

C
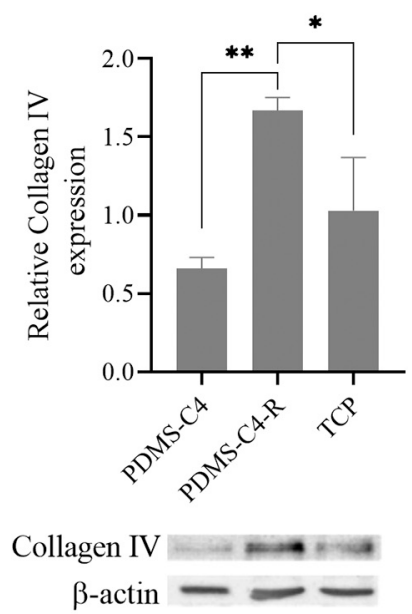

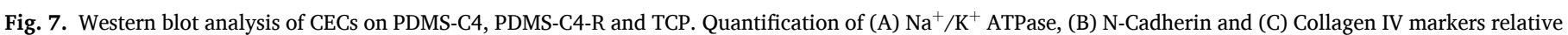
to $\beta$-actin $\left(n=3,{ }^{*} p<0.05\right.$ and $\left.* * p<0.01\right)$.

[51]. Furthermore, the density of these patterns $\left(\approx 2000\right.$ cells $\left./ \mathrm{mm}^{2}\right)$ was in the physiologically relevant range of corneal endothelium (well above the critical level, which is between 400 and 500 cells $/ \mathrm{mm}^{2}$ [64]), depth of hexagonal shapes $(\approx 6.6 \mu \mathrm{m})$, were similar to CECs $(\approx 5 \mu \mathrm{m})$ [43] and nanotopographical cues were naturally formed inside each hexagon [Fig. 3A(iii) and Fig. 3C(ii)]. SEM images of copies confirmed that a PDMS mold can be used for at least 10 times with excellent pattern fidelity (Fig. S1). Additionally, the effect of white rose petals with different growing stages on the corneal endothelium-like patterning were also examined in SI (Fig. S2) and no significant changes in pattern structure or dimensions were observed. However, in order to obtain a golden standard in patterning, investigation of the area in rose petals with the most appropriate topographical features and using it as a mold to produce substrates is necessary, as we did in Section 2.2.

For the production of cell substrates, we investigated Young's modulus of PDMS with various base and curing agent ratios, as cells are also responsive to the stiffness of their environment [11,65]. Palchesko et al. confirmed that substrates with Descemet's membrane-like chemomechanical properties resulted improved CEC behavior. Among other ECM proteins and substrates with various stiffness, Collagen IV coated PDMS with an elastic modulus of $50 \mathrm{kPa}$ was found to enhance CEC proliferation ( $>3000$ fold) and the expression of phenotypic markers [4]. We used 10:1 to 30:1 PDMS base to curing agent ratios in this study and 30:1 PDMS with 211.85 $\pm 74.9 \mathrm{kPa}$ Young's modulus (Fig. 4A) was accepted to be the cornea-friendly stiffness, where the bulk modulus range of cornea is between 200 and $290 \mathrm{kPa}$ [32,44-46]. Although the Young's modulus of the basement membrane underlying corneal endothelium (Descemet's membrane) was around $50 \mathrm{kPa}$ [4], all patterned cell substrates were prepared using 30:1 PDMS base to curing agent ratio. Because, using PDMS with lower curing agent amounts to achieve Descemet's membrane-like stiffness did not allow successful replication of rose mimetic topography. By adjusting PDMS stiffness to the corneafriendly range, biomimetic properties of cell substrates were enhanced.

In addition to the optimized topographical and mechanical properties of PDMS substrates, we have also functionalized their surfaces with two corneal ECM components: HA and COL 4. Although patterning resulted a significant increase in CEC proliferation ( $p<0.0001$, Fig. 5C) and the number of attached cells (Fig. 5D), actin fibers were disrupted on native PDMS and did not provide linking between adjacent cells, revealing the importance of surface chemical modification. Functionalization of PDMS surfaces with HA or COL 4 was completed using NHS/ EDC chemistry (Fig. 2) and demonstrated by WCA measurements, XPS analysis and immunofluorescent staining (Fig. 4B-H). The presence of N$\mathrm{C}=\mathrm{O}, \mathrm{C}=\mathrm{O}$ and the significant increase in $\mathrm{C}-\mathrm{N}$ and $\mathrm{C}-\mathrm{C}$ peaks in high resolution C1s spectra of PDMS-HA (Fig. 4F) and PDMS-C4 (Fig. 4G) indicated that modification was achieved successfully $[41,48,66]$. Fourier Transform Infrared Spectroscopy (FTIR) was also used to confirm XPS analysis (SI, Fig. S4). Additionally, wettability properties of HA and COL 4 modified PDMS (Fig. 4B) were consistent with the literature with hydrophilic PDMS-C4 [67] and relatively hydrophobic nature of PDMS-HA [68]. Digital images of substrates with native plain, functionalized plain and functionalized patterned PDMS were given in SI (Fig. S6) showing the optical transparency of samples. After successful functionalization of PDMS substrates with these corneal ECM components, proliferation of CECs was enhanced, as seen in Fig. 5A-C. This effect was more distinctive in PDMS-C4, as collagen type IV is one of the main constituents of Descemet's membrane [69]. Accordingly, PDMS-C4 successfully mimics the natural microenvironment of CECs. Among all flat PDMS substrates, PDMS-C4 provided the most suitable environment for CEC expansion (Fig. 5A), whereas white rose patterning of PDMS-C4 enhanced proliferative capacity of CECs significantly $(p<0.0001)$ and showed similar effects with the control group, TCP (Fig. 5B and C). Although HA modification of PDMS did not change CEC metabolic activities, it ensured cellular attachment and better cytoskeleton formation, when compared to native PDMS (Fig. 5D). HA is a naturally occurring glycosaminoglycan and known to facilitate cell adhesion [16]. Especially on PDMS-HA-R, cell adhesion was considerably higher, due to the enhanced biomimetic properties of substrates. However, even flat PDMS-C4 provided better cell adhesion than patterned PDMS-HA, with improved interconnections between cells and increased attached cell number. Moreover, cells on patterned PDMS-C4 showed typical CEC polygonal shapes and formed a confluent cell monolayer, whereas elongated CEC shapes with relatively low number of cells were found on TCP. Actin cytoskeleton staining of CECs on patterned PDMS showed the guidance effect of white rose petal negative relief topography, with enhanced interconnections between adjacent cells and maintenance of uniform hexagonal CEC shape.

The PDMS-C4-R cell substrates were not only effective for in vitro CEC proliferation but also for their physiological functionality. $\mathrm{Na}^{+} / \mathrm{K}^{+}$ ATPase expression of cells on substrates was investigated to evaluate the activity and vitality of CECs. Localization of $\mathrm{Na}^{+} / \mathrm{K}^{+}$ATPase is very crucial for the regulation of corneal pumping function. This pump function prevents stroma from overhydration and maintains optical transparency [70]. Positive immunostaining of $\mathrm{Na}^{+} / \mathrm{K}^{+}$ATPase was observed on all substrates (Fig. 6); however, the staining intensity was higher in flat and patterned, COL 4 modified PDMS. Among all substrates including TCP, PDMS-C4-R facilitated the highest immunofluorescent intensity against $\mathrm{Na}^{+} / \mathrm{K}^{+}$ATPase, whereas both PDMS-C4-R and 
TCP showed similar CEC proliferation. Western blot analysis confirmed immunostaining results with enhanced CEC phenotype specific marker expressions arising from white rose petal mimicked surface topography (Fig. 7). Significantly higher up-regulations of healthy corneal endothelium related morphological and functional proteins of Collagen IV [9], $\mathrm{Na}^{+} / \mathrm{K}^{+}$ATPase [71] and N-Cadherin [5] indicated that combination of cornea-friendly substrate stiffness with biomimetic surface chemistry and topography predominates over the positive effects of TCP on CECs and PDMS-C4-R provided functional expansion of CECs.

In the literature, most of the studies which used different topographies to modulate CEC behavior have utilized patterned TCP or PDMS as a cell substrate [12,27,62] PDMS substrates with round pillars and Laminin-1 coating had the highest bovine CEC density among other patterns like gratings, channels, and wells [27]. Koo et al. investigated the behavior of cells from human CEC line B4G12 on different topographies like nanopillars, microwells and micropillars on PDMS substrates with several ECM protein coatings. According to their results, cells exhibited higher proliferation rate when they cultured on $1 \mu \mathrm{m}$ pillar with the coating of FNC ${ }^{\circledR}$ coating mix compared to plain control substrates [62]. Another study reported that $1 \mu \mathrm{m}$ pillar patterns on TCP significantly increased proliferation rate of primary human CECs when compared to plain TCP [12]. Gelatin methacrylate (GelMA) hydrogel substrates were also used for primary human CECs. They reported that the expression of $\mathrm{Na}^{+} / \mathrm{K}^{+}$ATPase was higher on substrates with squarearray of $1 \mu \mathrm{m}$ pillars with $6 \mu \mathrm{m}$ spacing and hexagonal-array of $1 \mu \mathrm{m}$ pillars with $6 \mu \mathrm{m}$ spacing, when compared to plain control group [72]. Furthermore, in our previous work, we prepared hexagonal wellpatterned polyacrylamide (PA) cell substrates via bioinspiration approach to enhance CEC proliferation. Substrates with physiologically relevant pattern density provided the most favorable cellular results in terms of cell density and cell proliferation [74]. In addition to abovementioned cell substrates, several substrate materials such as polyurethane, silicon surfaces, polycaprolactone, chitosan, polystyrene with various feature type and dimensions were studied for corneal stromal or epithelial cell types to examine the effect of topography [73]. The advantage of our substrates is that white rose petals have naturally occurring, mostly hexagonal shaped patterns similar to the topography of healthy corneal endothelium. This topography provides the most closely resembling patterns of the native tissue and it does not require a complicated production technique.

As a limitation of the study, a bovine CEC line was used as a cell model, instead of a human CEC line or primary CECs. There would be ethical issues and a need of an age-range-specific high cell numbers for this kind of a large screening study with primary CECs. Since bovine CECs have been studied extensively in this area, they were chosen to perform this comprehensive investigation and for a comparison of the effects of these substrates with the existing literature. The results in this study provide knowledge for prospective in vitro or in vivo studies with other CEC lines and primary CECs. In conclusion, to the best of authors' knowledge, similarities between white rose petal topography and natural healthy CEC microenvironment have been demonstrated in this study for the first time in the literature. These mimicked micro- and nanoscale architectures on substrate surfaces were obtained without any need of a donor. Here, we enhanced CEC-substrate characteristics of PDMS, which has been a widely used polymer for corneal applications, due to its good optical transparency, non-toxicity and biocompatibility, with a biomimetic approach, by optimizing mechanical, topographical and biochemical properties. These substrates would be promising alternatives for in vitro CEC expansion and ocular drug investigations.

\section{CRediT authorship contribution statement}

M. Özgen Öztürk-Öncel: Conceptualization, methodology, data curation, writing- original draft preparation; Fatma Zehra Erkoc-Biradli: Helped to methodology, data interpretation, writing- review \& editing; Rıfat Rasier: Review \& editing; Merve Marçalı: Helped to data interpretation, review \& editing; Çağlar Elbüken: Supervised profilometry data curation and interpretation, review \& editing; Bora Garipcan: Supervision, project administration, review \& editing.

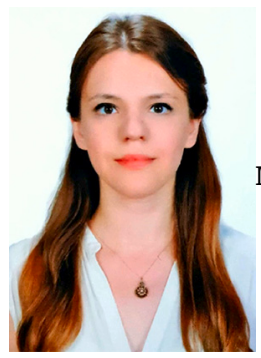

M. Özgen Öztürk-Öncel received her BSc de-

gree in Chemical Engineering from Hacettepe University in 2011 and MSc degree in Biomedical Engineering from Bogazici University in 2014. She completed her PhD studies on bioinspired and biomimetic cell substrate design for specific cell types in Biomedical Engineering from Bogazici University in 2021. Her research interests include biomimetic materials, cell-surface interactions and cell-type specific biomaterial design.

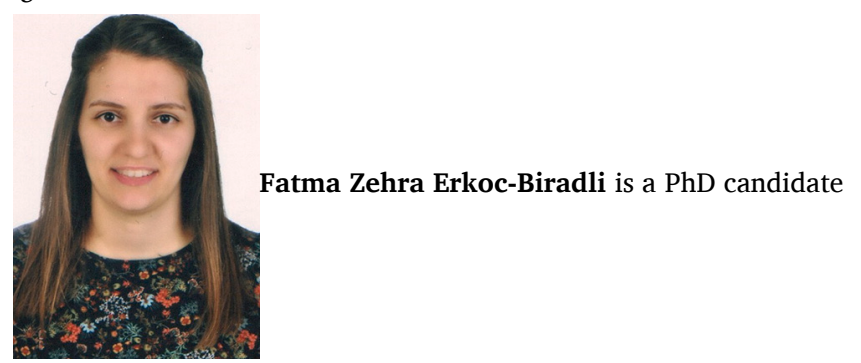

at Biomedical Engineering Institute, Bogazici University. She graduated from Yıldız Technical University, Department of Bioengineering in 2013. She received her MSc degree in Biomedical Engineering from Bogazici University in 2017. Her research interests include cornea tissue engineering, biomimetic and bioinspired materials, and threedimensional bioprinting technology.

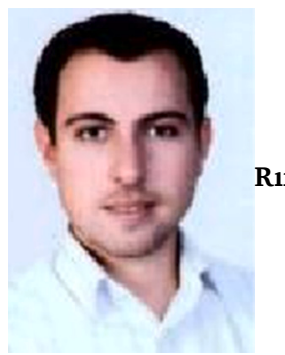

ulty of Medicine in 2004, and received ophthalmologist degree from Demiroglu Bilim University in 2010. In the same period, graduated from Boğazici University Biomedical Engineering master degree (MSc) in 2010, and $\mathrm{PhD}$ degree in 2018. Received associate professor degree in 2016 and currently working as an ophthalmologist at Florence Nightingale Hospital and lecturer at Demiroglu Bilim University. Main fields in ophthalmology are anterior segment, cornea and refractive surgery, and main fields in biomedical engineering are biophotonics and biomaterials. Received best publication award in 2010 and 2011 nationwide and received best thesis award at Bogazici University in 2017.

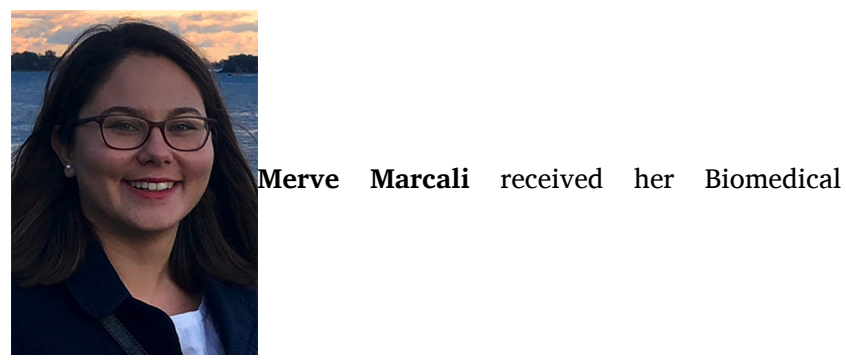


Engineering degree from Baskent University in 2013. In 2015, she completed her Master's degree in Material Science and Nanotechnology Department at UNAM (National Nanotechnology Center), Bilkent University. In 2020, she received her Ph.D. in Mechanical and Mechatronics Engineering department from the University of Waterloo on developing droplet based quantification methods for diagnostics. Her research interest is microfluidics for the study of lab on a chip devices and point of care.

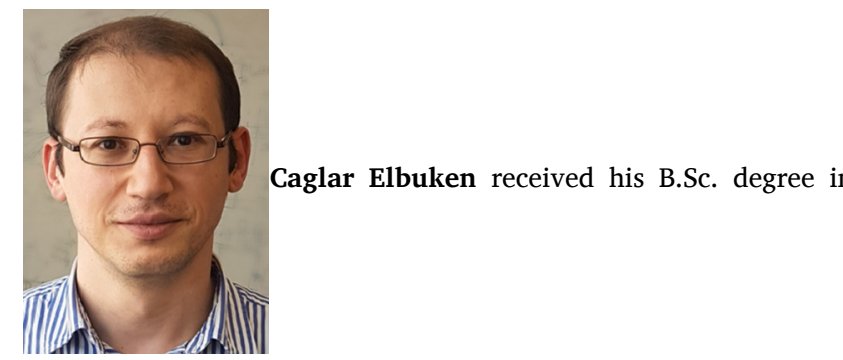

Electrical and Electronics Engineering from Bilkent University and his Ph.D. degree in Mechanical and Mechatronics Engineering from University of Waterloo. He worked as a postdoctoral associate at the Waterloo Microfluidics Laboratory before joining to Abbott Point-of-Care as a senior R\&D scientist. Since 2012, he has been leading the microfluidics research group at Bilkent University, National Nanotechnology Research Center (UNAM). He is currently a Professor at University of Oulu, Faculty of Biochemistry and Molecular Medicine and Faculty of Medicine. His research interests include biosensors, lab-on-a-chip devices, microdroplet-based microfluidic systems and viscoelasticity.

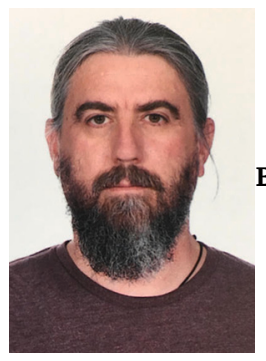

University, Department of Chemistry in 1999. He completed his MSc. Degree in Biochemistry division at the same department in 2001. He received his $\mathrm{PhD}$ in 2008 from Hacettepe University, Institute of Graduate and Applied Sciences Bioengineering division. He was PostDoctoral fellow in Friedrich-Schiller University, Institute of Materials Science and Technology, Jena, Germany between 2008 and 2009. He is an associate Prof. Dr. at Institute of Biomedical Engineering, Boğaziçi University, Istanbul, Turkey. His main research areas are; Biomaterials, Bioinspired and Biomimetic materials, Biosensors and Nanomaterials and focused on cell-surface interactions.

\section{Declaration of competing interest}

The authors declare that they have no known competing financial interests or personal relationships that could have appeared to influence the work reported in this paper.

\section{Acknowledgments}

This study was supported by Bogazici University Research Fund by Grant Numbers 11501 and 6701.

\section{Appendix A. Supplementary data}

Supplementary data to this article can be found online at https://doi. org/10.1016/j.msec.2021.112147.

\section{References}

[1] Y.-T. Tsao, C.-M. Cheng, W.-C. Wu, H.-C. Chen, Bioengineering of human corneal endothelial cells from single- to four-dimensional cultures, Curr. Ophthalmol. Rep. 8 (2020) 172-184, https://doi.org/10.1007/s40135-020-00244-y.

[2] J.A. Sanchis-Gimeno, A. Lleó-Pérez, L. Alonso, M.S. Rahhal, F. Martínez Soriano, Corneal endothelial cell density decreases with age in emmetropic eyes., Histol, Histopathol. 20 (2005) 423-427, https://doi.org/10.14670/HH-20.423.

[3] A.E.K. Hutcheon, J.D. Zieske, X. Guo, 3D in vitro model for human corneal endothelial cell maturation, Exp, Eye Res. 184 (2019) 183-191, https://doi.org/ 10.1016/j.exer.2019.04.003.

[4] R.N. Palchesko, K.L. Lathrop, J.L. Funderburgh, A.W. Feinberg, In vitro expansion of corneal endothelial cells on biomimetic substrates, Sci. Rep. 5 (2015) 7955, https://doi.org/10.1038/srep07955.

[5] P. Sun, L. Shen, C. Zhang, L. Du, X. Wu, Promoting the expansion and function of human corneal endothelial cells with an orbital adipose-derived stem cellconditioned medium, Stem Cell Res Ther 8 (2017) 287, https://doi.org/10.1186/ s13287-017-0737-5.

[6] B. Van den Bogerd, S.N. Dhubhghaill, C. Koppen, M.-J. Tassignon, N. Zakaria, A review of the evidence for in vivo corneal endothelial regeneration, Surv, Ophthalmol. 63 (2018) 149-165, https://doi.org/10.1016/j. survophthal.2017.07.004.

[7] G.S.L. Peh, R.W. Beuerman, A. Colman, D.T. Tan, J.S. Mehta, Human corneal endothelial cell expansion for corneal endothelium transplantation: an overview, Transplantation. 91 (2011) 811-819, https://doi.org/10.1097/ TP.0b013e3182111f01.

[8] N. Okumura, D. Matsumoto, Y. Fukui, M. Teramoto, H. Imai, T. Kurosawa, T. Shimada, F. Kruse, U. Schlötzer-Schrehardt, S. Kinoshita, N. Koizumi, Feasibility of cell-based therapy combined with descemetorhexis for treating Fuchs endothelial corneal dystrophy in rabbit model, PLoS One 13 (2018), e0191306, https://doi.org/10.1371/journal.pone.0191306.

[9] Y.-H. Wang, T.-H. Young, T.-J. Wang, Investigating the effect of chitosan/ polycaprolactone blends in differentiation of corneal endothelial cells and extracellular matrix compositions, Exp. Eye Res. 185 (2019), 107679, https://doi. org/10.1016/j.exer.2019.05.019.

[10] Z. Chen, X. Liu, J. You, Y. Song, E. Tomaskovic-Crook, G. Sutton, J.M. Crook, G. G. Wallace, Biomimetic corneal stroma using electro-compacted collagen, Acta Biomater. 113 (2020) 360-371, https://doi.org/10.1016/j.actbio.2020.07.004.

[11] S.S. Mahdavi, M.J. Abdekhodaie, S. Mashayekhan, A. Baradaran-Rafii, A. R. Djalilian, Bioengineering approaches for corneal regenerative medicine, Tissue Eng. Regen. Med. 17 (2020) 567-593, https://doi.org/10.1007/s13770-02000262-8.

[12] R. Muhammad, G.S.L. Peh, K. Adnan, J.B.K. Law, J.S. Mehta, E.K.F. Yim, Microand nano-topography to enhance proliferation and sustain functional markers of donor-derived primary human corneal endothelial cells, Acta Biomater. 19 (2015) 138-148, https://doi.org/10.1016/j.actbio.2015.03.016.

[13] M. Rafat, F. Li, P. Fagerholm, N.S. Lagali, M.A. Watsky, R. Munger, T. Matsuura, M. Griffith, PEG-stabilized carbodiimide crosslinked collagen-chitosan hydrogels for corneal tissue engineering, Biomaterials. 29 (2008) 3960-3972, https://doi. org/10.1016/j.biomaterials.2008.06.017.

[14] T.-J. Wang, I.-J. Wang, S. Chen, Y.-H. Chen, T.-H. Young, The phenotypic response of bovine corneal endothelial cells on chitosan/polycaprolactone blends, Colloids Surf. B: Biointerfaces 90 (2012) 236-243, https://doi.org/10.1016/j. colsurfb.2011.10.043.

[15] L. Koivusalo, J. Karvinen, E. Sorsa, I. Jönkkäri, J. Väliaho, P. Kallio, T. Ilmarinen, S. Miettinen, H. Skottman, M. Kellomäki, Hydrazone crosslinked hyaluronan-based hydrogels for therapeutic delivery of adipose stem cells to treat corneal defects, Mater. Sci. Eng. C. 85 (2018) 68-78, https://doi.org/10.1016/j.msec.2017.12.013.

[16] Y. Liu, L. Ren, Y. Wang, Crosslinked collagen-gelatin-hyaluronic acid biomimetic film for cornea tissue engineering applications, Mater. Sci. Eng. C Mater. Biol. Appl. 33 (2013) 196-201, https://doi.org/10.1016/j.msec.2012.08.030.

[17] J.-H. An, S.-Y. Park, G.-H. Kim, I.-P. Mo, S. Kim, H.-M. Woo, K.-M. Park, Tissue engineered ultra-thin descemet stripping corneal endothelial layers using porcine cornea and stem cells, Exp, Eye Res. 199 (2020), 108192, https://doi.org/ 10.1016/j.exer.2020.108192.

[18] I.M. El-Sherbiny, M.H. Yacoub, Hydrogel scaffolds for tissue engineering: Progress and challenges, Glob. Cardiol. Sci. Pract. 2013 (2013) 38. doi:https://doi.org/1 $0.5339 /$ gcsp. 2013.38 .

[19] R. Alexander, The gecko's foot. bio-inspiration: engineered from nature by Peter Forbes, Nature (London) 1 (2005) 166.

[20] Inspired by Biology, National Academies Press, Washington, D.C, 2008, https:// doi.org/10.17226/12159.

[21] N. Suresh Kumar, R. Padma Suvarna, K. Chandra Babu Naidu, P. Banerjee, A. Ratnamala, H. Manjunatha, A review on biological and biomimetic materials and their applications, Appl. Phys. A Mater. Sci. Process. 126 (2020) 445, https:// doi.org/10.1007/s00339-020-03633-z.

[22] D. Jhala, H. Rather, D. Kedaria, J. Shah, S. Singh, R. Vasita, Biomimetic polycaprolactone-chitosan nanofibrous substrate influenced cell cycle and ECM secretion affect cellular uptake of nanoclusters, Bioact. Mater. 4 (2019) 79-86, https://doi.org/10.1016/j.bioactmat.2018.12.004.

[23] Y. Liu, H. Gu, Y. Jia, J. Liu, H. Zhang, R. Wang, B. Zhang, H. Zhang, Q. Zhang, Design and preparation of biomimetic polydimethylsiloxane (PDMS) films with superhydrophobic, self-healing and drag reduction properties via replication of shark skin and SI-ATRP, Chem. Eng. J. 356 (2019) 318-328, https://doi.org/ 10.1016/j.cej.2018.09.022. 
[24] J. Teichmann, M. Valtink, M. Nitschke, S. Gramm, R. Funk, K. Engelmann, C. Werner, Tissue engineering of the corneal endothelium: a review of carrier materials, J. Funct. Biomater. 4 (2013) 178-208, https://doi.org/10.3390/ jfb4040178.

[25] A.J. Engler, C. Carag-Krieger, C.P. Johnson, M. Raab, H.-Y. Tang, D.W. Speicher, J. W. Sanger, J.M. Sanger, D.E. Discher, Embryonic cardiomyocytes beat best on a matrix with heart-like elasticity: scar-like rigidity inhibits beating, J. Cell Sci. 121 (2008) 3794-3802, https://doi.org/10.1242/jcs.029678.

[26] A.J. Engler, S. Sen, H.L. Sweeney, D.E. Discher, Matrix elasticity directs stem cell lineage specification, Cell. 126 (2006) 677-689, https://doi.org/10.1016/j cell.2006.06.044.

[27] B.K.K. Teo, K.J. Goh, Z.J. Ng, S. Koo, E.K.F. Yim, Functional reconstruction of corneal endothelium using nanotopography for tissue-engineering applications, Acta Biomater. 8 (2012) 2941-2952, https://doi.org/10.1016/j. actbio.2012.04.020.

[28] A. Gutermuth, J. Maassen, E. Harnisch, D. Kuhlen, A. Sauer-Budge, C. SkazikVoogt, K. Engelmann, Descemet's membrane biomimetic microtopography differentiates human mesenchymal stem cells into corneal endothelial-like cells, Cornea. 38 (2019) 110-119, https://doi.org/10.1097/ICO.0000000000001765.

[29] M.Ö. Öztürk Öncel, B. Garipcan, Stem cell behavior on microenvironment mimicked surfaces, Adv. Surfaces Stem Cell Res. (2016) 425-452, https://doi.org/ 10.1002/9781119242642.ch15.

[30] L. Gitlin, P. Schulze, D. Belder, Rapid replication of master structures by double casting with PDMS, Lab Chip 9 (2009) 3000, https://doi.org/10.1039/b904684d.

[31] M.Ö. Öztürk-Öncel, S. Odabaș, L. Uzun, D. Hür, B. Garipcan, A facile surface modification of poly(dimethylsiloxane) with amino acid conjugated self-assembled monolayers for enhanced osteoblast cell behavior, Colloids Surf. B: Biointerfaces 196 (2020), 111343, https://doi.org/10.1016/j.colsurfb.2020.111343.

[32] J.A. Last, S.J. Liliensiek, P.F. Nealey, C.J. Murphy, Determining the mechanical properties of human corneal basement membranes with atomic force microscopy, J. Struct. Biol. 167 (2009) 19-24, https://doi.org/10.1016/j.jsb.2009.03.012.

[33] Y.M. Park, M. Gang, Y.H. Seo, B.H. Kim, Artificial petal surface based on hierarchical micro- and nanostructures, Thin Solid Films 520 (2011) 362-367, https://doi.org/10.1016/j.tsf.2011.07.013.

[34] D. Ebert, B. Bhushan, Wear-resistant rose petal-effect surfaces with superhydrophobicity and high droplet adhesion using hydrophobic and hydrophilic nanoparticles, J. Colloid Interface Sci. 384 (2012) 182-188, https:// doi.org/10.1016/j.jcis.2012.06.070.

[35] M. Karaman, N. Çabuk, D. Özyurt, Ö. Köysüren, Self-supporting superhydrophobic thin polymer sheets that mimic the nature's petal effect, Appl. Surf. Sci. 259 (2012) 542-546, https://doi.org/10.1016/j.apsusc.2012.07.079.

[36] L. Feng, Y. Zhang, J. Xi, Y. Zhu, N. Wang, F. Xia, L. Jiang, Petal effect: a superhydrophobic state with high adhesive force, Langmuir. 24 (2008) 4114-4119, https://doi.org/10.1021/la703821h.

[37] J.-Y. Lai, Biofunctionalization of gelatin microcarrier with oxidized hyaluronic acid for corneal keratocyte cultivation, Colloids Surf. B: Biointerfaces 122 (2014) 277-286, https://doi.org/10.1016/j.colsurfb.2014.07.009.

[38] M.Ö. Öztürk-Öncel, C.O. Heras-Bautista, L. Uzun, D. Hür, J. Hescheler, K. Pfannkuche, B. Garipcan, Impact of poly(dimethylsiloxane) surface modification with conventional and amino acid-conjugated self-assembled monolayers on the differentiation of induced pluripotent stem cells into cardiomyocytes, ACS Biomater. Sci. Eng. (2021) acsbiomaterials.0c01434. doi:https://doi.org/10.1021/ acsbiomaterials.0c01434.

[39] P.J. Wipff, H. Majd, C. Acharya, L. Buscemi, J.J. Meister, B. Hinz, The covalent attachment of adhesion molecules to silicone membranes for cell stretching applications, Biomaterials. 30 (2009) 1781-1789, https://doi.org/10.1016/j. biomaterials.2008.12.022.

[40] Y.J. Chuah, S. Kuddannaya, M.H.A. Lee, Y. Zhang, Y. Kang, The effects of poly (dimethylsiloxane) surface silanization on the mesenchymal stem cell fate, Biomater. Sci. 3 (2015) 383-390, https://doi.org/10.1039/C4BM00268G.

[41] Z. Yue, X. Liu, P.J. Molino, G.G. Wallace, Bio-functionalisation of polydimethylsiloxane with hyaluronic acid and hyaluronic acid - collagen conjugate for neural interfacing, Biomaterials. 32 (2011) 4714-4724, https://doi. org/10.1016/j.biomaterials.2011.03.032.

[42] F. Sarvi, Z. Yue, K. Hourigan, M.C. Thompson, P.P.Y. Chan, Surfacefunctionalization of PDMS for potential micro-bioreactor and embryonic stem cell culture applications, J. Mater. Chem. B 1 (2013) 987-996, https://doi.org/ 10.1039/C2TB00019A.

[43] A.O. Eghrari, S.A. Riazuddin, J.D. Gottsch, Overview of the Cornea: Structure, Function, and Development, 1st ed., Elsevier Inc., 2015. doi:https://doi.org/10.10 16/bs.pmbts.2015.04.001.

[44] N.E. Knox Cartwright, J.R. Tyrer, J. Marshall, Age-related differences in the elasticity of the human cornea, Investig. Opthalmology Vis. Sci. 52 (2011) 4324, https://doi.org/10.1167/iovs.09-4798.

[45] P.-J. Shih, C.-J. Huang, T.-H. Huang, H.-C. Lin, J.-Y. Yen, I.-J. Wang, H.-J. Cao, W. P. Shih, C.-A. Dai, Estimation of the corneal Young's modulus in vivo based on a fluid-filled spherical-shell model with Scheimpflug imaging, J. Ophthalmol. 2017 (2017) 1-11. doi:https://doi.org/10.1155/2017/5410143.

[46] K.E. Hamilton, D.C. Pye, Young's modulus in normal corneas and the effect on applanation tonometry, Optom. Vis. Sci. 85 (2008) 445-450, https://doi.org/ 10.1097/OPX.0b013e3181783a70.

[47] A. Scarano, F. Lorusso, T. Orsini, M. Morra, G. Iviglia, L. Valbonetti, Biomimetic surfaces coated with covalently immobilized collagen type I: an X-ray photoelectron spectroscopy, atomic force microscopy, micro-CT and histomorphometrical study in rabbits, Int. J. Mol. Sci. 20 (2019) 724, https://doi org/10.3390/ijms20030724.
[48] N. Marín-Pareja, E. Salvagni, J. Guillem-Marti, C. Aparicio, M.-P. Ginebra, Collagen-functionalised titanium surfaces for biological sealing of dental implants: effect of immobilisation process on fibroblasts response, Colloids Surf. B: Biointerfaces 122 (2014) 601-610, https://doi.org/10.1016/j. colsurfb.2014.07.038.

[49] D. Sharma, W. Jia, F. Long, S. Pati, Q. Chen, Y. Qyang, B. Lee, C.K. Choi, F. Zhao, Polydopamine and collagen coated micro-grated polydimethylsiloxane for human mesenchymal stem cell culture, Bioact. Mater. 4 (2019) 142-150, https://doi.org/ 10.1016/j.bioactmat.2019.02.002.

[50] Z. Qian, D. Ross, W. Jia, Q. Xing, F. Zhao, Bioactive polydimethylsiloxane surface for optimal human mesenchymal stem cell sheet culture, Bioact. Mater. 3 (2018) 167-173, https://doi.org/10.1016/j.bioactmat.2018.01.005.

[51] M. Parekh, S. Ferrari, C. Sheridan, S. Kaye, S. Ahmad, Concise review: an update on the culture of human corneal endothelial cells for transplantation, Stem Cells Transl. Med. 5 (2016) 258-264, https://doi.org/10.5966/sctm.2015-0181.

[52] M. Nikkhah, F. Edalat, S. Manoucheri, A. Khademhosseini, Engineering microscale topographies to control the cell-substrate interface, Biomaterials. 33 (2012) 5230-5246, https://doi.org/10.1016/j.biomaterials.2012.03.079.

[53] M. Mirbagheri, V. Adibnia, B.R. Hughes, S.D. Waldman, X. Banquy, D.K. Hwang, Advanced cell culture platforms: a growing quest for emulating natural tissues, Mater. Horiz. 6 (2019) 45-71, https://doi.org/10.1039/C8MH00803E.

[54] V.A. Schulte, M. Díez, M. Möller, M.C. Lensen, Surface topography induces fibroblast adhesion on intrinsically nonadhesive poly(ethylene glycol) substrates, Biomacromolecules. 10 (2009) 2795-2801, https://doi.org/10.1021/bm900631s.

[55] J.L. Charest, M.T. Eliason, A.J. García, W.P. King, Combined microscale mechanical topography and chemical patterns on polymer cell culture substrates, Biomaterials. 27 (2006) 2487-2494, https://doi.org/10.1016/j. biomaterials.2005.11.022.

[56] R.J. McMurray, N. Gadegaard, P.M. Tsimbouri, K.V. Burgess, L.E. McNamara, R. Tare, K. Murawski, E. Kingham, R.O.C. Oreffo, M.J. Dalby, Nanoscale surfaces for the long-term maintenance of mesenchymal stem cell phenotype and multipotency, Nat. Mater. 10 (2011) 637-644, https://doi.org/10.1038/ nmat3058.

[57] S. Xiong, H.C. Gao, L. Qin, Y.G. Jia, L. Ren, Engineering topography: effects on corneal cell behavior and integration into corneal tissue engineering, Bioact. Mater. 4 (2019) 293-302, https://doi.org/10.1016/j.bioactmat.2019.10.001.

[58] S.J. Liliensiek, S. Campbell, P.F. Nealey, C.J. Murphy, The scale of substratum topographic features modulates proliferation of corneal epithelial cells and corneal fibroblasts, J. Biomed. Mater. Res. A. 79A (2006) 185-192, https://doi.org/ 10.1002/jbm.a.30744.

[59] P. Eberwein, T. Steinberg, S. Schulz, D. Zimmermann, R. Accardi, D. Beck, T. Reinhard, P. Tomakidi, Expression of keratinocyte biomarkers is governed by environmental biomechanics, Eur. J. Cell Biol. 90 (2011) 1029-1040, https://doi. org/10.1016/j.ejcb.2011.08.005.

[60] A.I. Teixeira, P.F. Nealey, C.J. Murphy, Responses of human keratocytes to microand nanostructured substrates, J. Biomed. Mater. Res. 71A (2004) 369-376, https://doi.org/10.1002/jbm.a.30089.

[61] P. Bhattacharjee, B.L. Cavanagh, M. Ahearne, Effect of substrate topography on the regulation of human corneal stromal cells, Colloids Surf. B: Biointerfaces 190 (2020), 110971, https://doi.org/10.1016/j.colsurfb.2020.110971.

[62] S. Koo, R. Muhammad, G.S.L.L. Peh, J.S. Mehta, E.K.F.F. Yim, Micro- and nanotopography with extracellular matrix coating modulate human corneal endothelial cell behavior, Acta Biomater. 10 (2014) 1975-1984, https://doi.org/ 10.1016/j.actbio.2014.01.015.

[63] G.A. Abrams, S.S. Schaus, S.L. Goodman, P.F. Nealey, C.J. Murphy, Nanoscale topography of the corneal epithelial basement membrane and Descemet's membrane of the human, Cornea. 19 (2000) 57-64, https://doi.org/10.1097/ 00003226-200001000-00012.

[64] J. Zavala, G. Ló Pez Jaime, C.R. Barrientos, J. Valdez-Garcia, Corneal endothelium: developmental strategies for regeneration, Eye. 27 (2013) 579-588, https://doi. org/10.1038/eye.2013.15.

[65] R. Chen, L. Li, L. Feng, Y. Luo, M. Xu, K.W. Leong, R. Yao, Biomaterial-assisted scalable cell production for cell therapy, Biomaterials. 230 (2020), 119627, https://doi.org/10.1016/j.biomaterials.2019.119627.

[66] M. Morra, C. Cassinelli, G. Cascardo, P. Cahalan, L. Cahalan, M. Fini, R. Giardino, Surface engineering of titanium by collagen immobilization. Surface characterization and in vitro and in vivo studies, Biomaterials. 24 (2003) 4639-4654, https://doi.org/10.1016/S0142-9612(03)00360-0.

[67] C. Li, Y. Ding, S. Kuddannaya, Y. Zhang, L. Yang, Anti-bacterial properties of collagen-coated glass and polydimethylsiloxane substrates, J. Mater. Sci. 52 (2017) 9963-9978, https://doi.org/10.1007/s10853-017-1175-6.

[68] P. Xue, Q. Li, Y. Li, L. Sun, L. Zhang, Z. Xu, Y. Kang, Surface modification of poly (dimethylsiloxane) with polydopamine and hyaluronic acid to enhance hemocompatibility for potential applications in medical implants or devices, ACS Appl. Mater. Interfaces 9 (2017) 33632-33644, https://doi.org/10.1021/ acsami.7b10260.

[69] S. Ponce Márquez, V.S. Martínez, W. McIntosh Ambrose, J. Wang, N.G. Gantxegui, O. Schein, J. Elisseeff, Decellularization of bovine corneas for tissue engineering applications, Acta Biomater. 5 (2009) 1839-1847, https://doi.org/10.1016/j. actbio.2009.02.011.

[70] J.A. Bonanno, Molecular mechanisms underlying the corneal endothelial pump, Exp. Eye Res. 95 (2012) 2-7, https://doi.org/10.1016/j.exer.2011.06.004.

[71] Y.-J. Hsueh, D.H.-K. Ma, K.S.-C. Ma, T.-K. Wang, C.-H. Chou, C.-C. Lin, M.C. Huang, L.-J. Luo, J.-Y. Lai, H.-C. Chen, Extracellular matrix protein coating of processed fish scales improves human corneal endothelial cell adhesion and 
proliferation, Transl. Vis. Sci. Technol. 8 (2019) 27, https://doi.org/10.1167/ tvst.8.3.27.

[72] M. Rizwan, G.S.L. Peh, H.P. Ang, N.C. Lwin, K. Adnan, J.S. Mehta, W.S. Tan, E.K. F. Yim, Sequentially-crosslinked bioactive hydrogels as nano-patterned substrates with customizable stiffness and degradation for corneal tissue engineering applications, Biomaterials. 120 (2017) 139-154, https://doi.org/10.1016/j. biomaterials.2016.12.026.
[73] S. Xiong, H. Gao, L. Qin, Y.-G. Jia, L. Ren, Engineering topography: effects on corneal cell behavior and integration into corneal tissue engineering, Bioact. Mater. 4 (2019) 293-302, https://doi.org/10.1016/j.bioactmat.2019.10.001.

[74] F.Z. Erkoc-Biradli, A. Ozgun, M.Ö. Öztürk-Öncel, M. Marcali, C. Elbuken, O. Bulut, R. Rasier, B. Garipcan, Bioinspired hydrogel surfaces to augment corneal endothelial cell monolayer formation. J. Tissue Eng. Regen. Med. (2021) https:// doi.org/10.1002/term.3173. 